\title{
PROSES PENGAMBILAN KEPUTUSAN PEMBELIAN SAYURAN HIDROPONIK DI KOTA BANDAR LAMPUNG
}

\author{
DECISION MAKING PROCESS OF HYDROPONIC VEGETABLES IN \\ BANDAR LAMPUNG CITY \\ Sutarni $^{1}$, Luluk Irawati ${ }^{2}$, Bina Unteawati ${ }^{3}$, Clara Yolandika ${ }^{4}$ \\ ${ }^{1,2,3,4}$ Politeknik Negeri Lampung \\ e-mail: *1 sutarni @ polinela.ac.id
}

\begin{abstract}
The purpose of this study is to describe the decision making process of purchasing hydroponic vegetables. This research conducted in Bandar Lampung City. The study was conducted on 42 consumers of hydroponic vegetables and 42 non-hydroponic consumers. This research requires a qualitative method approach. Analysis of the stages of consumer purchasing decision-making process used to determine consumer behavior in making purchases of hydroponic and non hydroponic vegetables. Stages in the process of making consumer purchasing decisions in choosing commodities include the introduction of needs, information search, alternative evaluation, purchasing decisions, and postpurchase evaluation.
\end{abstract}

Keywords: Decission Making, Hydroponic, Vegetable

Disubmit :30 April 2018 Diterima:30 Maret 2018, Disetujui :1 April 2018

\section{PENDAHULUAN}

Salah satu sistem pertanian yang dikembangkan di Daerah Perkotaan pada saat ini adalah sistem pertanian hidroponik. Tanaman hidroponik merupakan tanaman yang menggunakan air atau media non tanah sebagai tempat hidupnya. "Hydro" sendiri bersal dari bahasa Yunani yang berarti air. Jadi tanaman ini menggunakan media air sebagai tempat hidup. Metode Tanaman Hidroponik merupakan metode yang ramah lingkungan karena tidak menggunakan pestisida. Sistem budidaya secara hidroponik sering diterapkan untuk mengatasi kekurangan lahan pertanian seperti di daerah perkotaan, yang dalam hal ini adalah tanaman pangan dalam khususnya sayuran. Budidaya pertanian yang menggunakan teknologi hidroponik tidak lepas dari sarana yang dapat menunjang optimalisasi dalam pertumbuhan dan perkembangan tanaman. Mengingat hidroponik ini bukan suatu keharusan, melainkan suatu jalan keluar, maka komoditi yang ditanam pun harus mempunyai pasar khusus dan harga khususpula.

Bertanam secara Hidroponik dapat berkembang dengan cepat, karena cara ini mempunyai banyak kelebihan. Kelebihan yang utama adalah tanaman dapat tumbuh dan berproduksi lebih baik dibandingkan dengan teknik penanaman biasa. Kelebihan lainnya yaitu perawatan lebih praktis dan gangguan hama lebih terkontrol, pemakaian pupuk lebih hemat, tanaman yang mati lebih mudah diganti dengan tanaman yang baru, tidak membutuhkan tenaga kasar karena metode kerja lebih hemat dan memiliki standardisasi, tanaman dapat tumbuh lebih pesat dan dengan keadaan yang tidak kotor dan rusak.

Sutarni dkk (Proses Pengambilan Keputusan Pembelian Sayuran Hidroponik Di Kota Bandar Lampung) 
Keuntungan hidroponik antara lain banyak variasi penanaman, pengendalian lebih baik, tanpa media tanah, hasil lebih besar, hasil seragam, lebih bersih, lebih sedikit tenaga kerja, hampir tidak ada rumput liar dan sebagai suatu pengembangan hobby.

Menurut Sengkey, M.Y. dkk (2017) bahwa persepsi masyarakat terhadap Hidroponik sangat baik dengan indeks persepsi 84,16\% dan tergolong dalam kategori sangat setuju. Masyarakat sangat setuju dengan adanya teknik pertanian dengan menggunakan Hidroponik, masyarakat berpendapat bahwa Hidroponik sangat bermanfaat bagi masyarakat karena dengan Hidroponik masyarakat dapat mengkonsumsi buah dan sayur yang sehat tanpa menggunakan produk-produk kimia, tidak perlu bersusah payah mencari lahan untuk bercocok tanam,dapat memanfaatkan barang-barang bekas di rumah, tidak membutuhkan waktu yang lama untuk berhidroponik, dan tidak menggunakan tanah seperti pertanian konvensional. Masalah lain dalam penerapan pertanian hidroponik dari sisi pasar yaitu kosumen dalam membeli produk pertanian hidroponik perlu pertimbangan yang panjang untuk memutuskannya. Artibut-artibut produk pertanian hidroponik pun mempengaruhi dalam proses pengambilan keputusan tersebut. Lebih lanjut Kaunang, S.G. dkk (2016) menyatakan faktor yang menyebabkan persepsi masyarakat di kategori baik kepada tanaman hidroponik antara lain responden mengerti tentang tanaman hidroponik dan bertanggapan persepsi lewat pengetahuaan tanaman hidroponik bahwa responden mengerti penanaman hidroponik serta keuntungan dan kelebihan dari pemanfaatan tanaman tersebut karena keuntungan dan kelebihannya yaitu harga jual yang lebih tinggi di bandingkan tanaman yang di tanam secara konvensional, tidak menggunakan pestisida, masa pertumbuhan lebih cepat, hasil lebih maksimal, bisa di tanam di musim apa pun, bisa ditanam di daerah perkotaan, cara pengurusan tanaman yang mudah hanya menjaga kestabilitas air serta penambahan nutrisi secara teratur. Dan menurut responden diera yang sudah seperti sekarang, harus di kembangkan tanaman hidroponik agar masyarakat juga bisa ikut menanam tanaman hidroponik dan agar kebutuhan pangan untuk masyarakat bisa lebih bertambah.

Perkembangan pertanian hidroponik di Kota Bandar Lampung masih terbatas. Salah satu produsen tanaman sayuran hidroponik di Kota Bandar Lampung adalah Alumni Politeknik Negeri Lampung yaitu Ketut Kamajaya yang beralamat di Perum BKP Blok S No. 136 Bandar Lampung. Jenis sayuran yang dikembangkan antara lain selada caisin, packcoy putih, packcoy hijau, packcoy mini, sawi keriting, dan pagoda yang dipasarkan ke swalayan Candra Tanjung Karang, Teluk, dan Mal Bumi Kedaton, serta kafe dan restro di Bandar Lampung. Selain itu, di Politeknik Negeri Lampung juga sedang mengembangkan tanaman hidroponik skala laboratorium. Oleh karena itu, untuk mengembangkan strategi pemasaran produk sayuran hidroponik tersebut, perlu diketahui terlebih dahulu perilaku konsumen. Pengambilan keputusan seorang konsumen dalam membeli produk hidroponik tentunya melalui tahapan panjang dan banyak faktor yang mempengaruhinya baik dari faktor Budaya (pendidikan), Sosial (pengaruh pihak lain), Pribadi (umur, jumlah pembelian, frekuensi pembelian), Psikologis (persepsi), dan Bauran Pemasaran: Produk (kesegaran produk), Harga (harga), Tempat (akses), dan Promosi. Berdasarkan uraian sebelumnya peneliti tertarik untuk meneliti tentang: perilaku konsumen dalam pembelian sayuran hidroponik di Kota Bandar Lampung.

\section{METODE}

Penelitian dilakukan di Kota Bandar Lampung, Provinsi Lampung Penentuan lokasi penelitian dilakukan secara purposive dengan dasar pertimbangan Kota Bandar Lampung merupakan ibukota provinsi yang merupakan sentra perekonomian Provinsi Lampung. Penelitian dilakukan pada beberapa tempat yang menjual sayuran hidroponik, seperti Chandra Teluk Betung, Chandra Mall Boemi Kedaton, Chandra Departemen Store

Sutarni dkk (Proses Pengambilan Keputusan Pembelian Sayuran Hidroponik Di Kota Bandar Lampung) 
Tanjung Karang, dan Politeknik Negeri Lampung. Penelitian dilakukan pada bulan Agustus sampai dengan November 2017.

Data yang digunakan dalam penelitian ini meliputi data primer. Data primer diperoleh melalui observasi dan wawancara secara langsung berdasarkan kuesioner kepada responden untuk memperoleh data tahapan proses pengambilan keputusan pembelian konsumen. Penentuan sampel responden dilakukan dengan menggunakan metode accidental sampling. Populasi sasaran adalah konsumen yang membeli sayuran hidroponik dan non hidroponik. Jumlah sampel yang digunakan adalah 42 orang konsumen yang membeli sayuran hidroponik dan 42 orang konsumen yang membeli sayuran non hidroponik, sehingga keseluruhan responden berjumlah 84 orang konsumen.

Penelitian ini membutuhkan pendekatan metode kualitatif. Analisis tahapan proses pengambilan keputusan pembelian konsumen digunakan untuk mengetahui perilaku konsumen dalam melakukan pembelian sayuran hidroponik dan non hidroponik. Tahapan dalam proses pengambilan keputusan pembelian konsumen dalam memilih komoditas meliputi pengenalan kebutuhan, pencarian informasi, evaluasi alternatif, keputusan pembelian, dan evaluasi pasca pembelian. Data diperoleh dari daftar pertanyaan yang diajukan melalui kuesioner dan disajikan dalam bentuk tabulasi dengan menggunakan analisis deskriptif.

\section{HASIL DAN PEMBAHASAN}

\section{Gambaran Umum Lokasi Penelitian}

Karakteristik konsumen dalam penelitian ini bertujuan untuk mengetahui keterkaitan antara karakteristik yang dimiliki oleh konsumen dengan tingkat persepsi, proses pengambilan keputusan pembelian, serta faktor-faktor yang mempengaruhi proses keputusan pembelian sayuran. Responden konsumen sayuran hidroponik dalam penelitian ini berjumlah 84 orang yang terdiri dari 42 konsumen sayuran hidroponik dan 42 konsumen sayuran non hidroponik. Responden diambil secara sengaja dengan metode accidental sampling pada beberapa supermarket dan produsen hidroponik di Kota Bandar Lampung.

Karakteristik konsumen yang dianggap penting untuk diketahui yaitu umur, jenis kelamin, tingkat pendidikan, dan pendapatan. Karakteristik dari masing-masing konsumen berbeda-beda, sehingga hal ini dapat mempengaruhi proses pengambilan keputusan konsumen dalam membeli sayuran.

\section{Proses Pengambilan Keputusan Pembelian}

Pengambilan keputusan konsumen dalam melakukan pembelian sayuran hidroponik dan non hidroponik melalui 5 tahapan, yaitu : pengenalan kebutuhan atau masalah, pencarian informasi, evaluasi alternatif, keputusan pembelian, dan perilaku pasca pembelian.

\section{Pengenalan Masalah/Kebutuhan}

Proses keputusan pembelian konsumen dalam memilih sayuran hidroponik dan non hidroponik diawali ketika konsumen mulai merasakan dan mengenali adanya kebutuhan akan suatu produk sayuran dan berusaha untuk memenuhi kebutuhan tersebut. Bagi masyarakat di Kota Bandar Lampung, mengkonsumsi sayuran sudah menjadi hal yang biasa bagi mereka. Pengenalan kebutuhan konsumen dalam pembelian sayuran sangat beragam sebagaimana dapat dilihat pada Tabel 1.

Pada konsumen yang mengkonsumsi sayuran hidroponik sebagian besar atau sekitar 59.52 persen adalah karena kualitasnya baik. Masyarakat menganggap sayuran yang memiliki kualitas yang baik merupakan sayuran yang baik untuk dikonsumsi.

Sutarni dkk (Proses Pengambilan Keputusan Pembelian Sayuran Hidroponik Di Kota Bandar Lampung) 
Hanya sebagian kecil, yaitu sekitar 26.19 persen yang mengkonsumsi sayuran hidroponik karena keanekaragamannya dan hanya 14.29 persen yang mengkonsumsi sayuran hidroponik karena sayuran hidroponik lebih bergizi.

Tabel 1. Pengenalan kebutuhan konsumen dalam pembelian sayuran hidroponik dan non hidroponik

\begin{tabular}{|c|c|c|c|c|c|}
\hline \multirow{2}{*}{ No } & \multirow{2}{*}{ Uraian } & \multicolumn{2}{|c|}{ Konsumen Sayuran Hidroponik } & \multicolumn{2}{|c|}{$\begin{array}{c}\text { Konsumen Sayuran Non } \\
\text { Hidroponik }\end{array}$} \\
\hline & & $\begin{array}{l}\text { Jumlah } \\
\text { (orang) }\end{array}$ & $\begin{array}{l}\text { Persentase } \\
\text { (persen) }\end{array}$ & $\begin{array}{l}\text { Jumlah } \\
\text { (orang) }\end{array}$ & $\begin{array}{l}\text { Persentase } \\
\text { (persen) }\end{array}$ \\
\hline 1 & $\begin{array}{cl}\text { Motivasi Mengkonsumsi Sayuran } \\
\text { - } & \text { Variasi Beraneka Ragam } \\
\text { - } & \text { Kualitas Baik } \\
\text { - } & \text { Lebih Bergizi }\end{array}$ & $\begin{array}{c}11 \\
25 \\
6\end{array}$ & $\begin{array}{l}26.19 \\
59.52 \\
14.29\end{array}$ & $\begin{array}{c}3 \\
29 \\
10\end{array}$ & $\begin{array}{c}7.14 \\
69.05 \\
23.81\end{array}$ \\
\hline 2 & $\begin{array}{cc}\text { Motivasi Membeli Sayuran } \\
\text { - } & \text { Harga terjangkau } \\
\text { - } & \text { Mudah didapat } \\
\text { - } & \text { Kemasan Baik } \\
\end{array}$ & $\begin{array}{c}23 \\
9 \\
10 \\
\end{array}$ & $\begin{array}{l}54.76 \\
21.43 \\
23.81 \\
\end{array}$ & $\begin{array}{c}18 \\
3 \\
21\end{array}$ & $\begin{array}{c}42.86 \\
7.14 \\
50.00 \\
\end{array}$ \\
\hline 3 & $\begin{array}{l}\text { Manfaat yang dicari } \\
\text { - } \quad \text { Lebih Sehat } \\
\text { - Tidak merusak lingkungan } \\
\text { - } \quad \begin{array}{l}\text { Mengurangi terkena hama } \\
\text { penyakit }\end{array}\end{array}$ & $\begin{array}{c}36 \\
3 \\
3\end{array}$ & $\begin{array}{c}85.71 \\
7.14 \\
7.14\end{array}$ & $\begin{array}{c}41 \\
0 \\
1\end{array}$ & $\begin{array}{c}97.62 \\
0 \\
2.38\end{array}$ \\
\hline
\end{tabular}

Sementara pada konsumen yang mengkonsumsi sayuran non hidroponik sebagian besar atau sekitar 69.05 persen adalah karena kualitasnya baik. Masyarakat menganggap sayuran yang memiliki kualitas yang baik merupakan sayuran yang baik untuk dikonsumsi. Hanya sebagian kecil, yaitu sekitar 7.14 persen yang mengkonsumsi sayuran non hidroponik karena keanekaragamannya dan hanya 23.81 persen yang mengkonsumsi sayuran hidroponik karena sayuran non hidroponik bergizi.

Kebutuhan terhadap sayuran didorong oleh bebarapa faktor. Salah satu perubahan yang cukup signifikan adalah mulai beralihnya pola konsumsi masyarakat dari mengkonsumsi sayuran yang berkadar gizi rendah menjadi sayuran berkualitas dan berkadar gizi tinggi (Yolandika \& Nurmalina, 2017) dan hal ini dipengaruhi oleh motivasi konsumen dalam membeli sayuran sebagaimana dapat dilihat pada Tabel 11. Berdasarkan hasil penelitian menunjukkan bahwa pada konsumen sayuran hidroponik, timbulnya motivasi konsumen dalam membeli sayuran hidroponik sebagian besar (54.76 persen) adalah karena harganya terjangkau, 23.81 persen karena kemasannya yang baik, dan 21.43 persen karena mudah didapat. Akan tetapi, pada konsumen sayuran non hidroponik, 50.00 persen adalah kemasannya baik, 42.86 persen karena harga terjangkau, dan 7.14 persen karena mudah didapat. Konsumen sayuran hidroponik dan non hidroponik menunjukkan adanya kesamaan motivasi dalam pembelian sayuran.

Manfaat yang dicari konsumen dalam pembelian sayuran, bagi konsumen sayuran hidroponik sebagian besar adalah karena sayuran hidroponik lebih sehat (85.71 persen). Selain itu sebanyak 7.14 persen karena sayuran hidroponik tidak merusak lingkungan, dan 7.14 persen karena sayuran hidroponik dapat mengurangi hama penyakit. Sama dengan sayuran non hidroponik, sebagian besar (97.62) konsumen sayuran non hidroponik sebagian besar adalah karena sayuran non hidroponik lebih sehat dan sisanya sebanyak 2.38 persen karena sayuran hidroponik dapat mengurangi hama penyakit. Menurut Ancok (1997), adanya pengetahuan tentang manfaat sesuatu hal akan menyebabkan seseorang bersikap positif terhadap hal tersebut.

\section{Pencarian Informasi Sayuran}

Pada tahap ini konsumen akan melakukan pencarian informasi mengenai keunggulan dan kelemahan sayuran yang akan dikonsumsi sehari-hari.

Sutarni dkk (Proses Pengambilan Keputusan Pembelian Sayuran Hidroponik Di Kota Bandar Lampung) 
Perolehan informasi akan mempengaruhi persepsi konsumen bahkan keyakinannya terhadap sayuran, sehingga pada akhirnya akan mempengaruhi keputusannya dalam pembelian sayuran.

Berdasarkan hasil penelitian, sumber informasi yang paling berpengaruh bagi konsumen sayuran hidroponik yaitu diri sendiri (35.71 persen), kemudian sumber informasi yang berasal dari pedagang sayuran sebanyak 23.81 persen, sumber informasi dari media cetak/elektronik sebanyak 21.43 persen, dan sumber informasi dari teman/keluarga sebanyak 19.05 persen. Teman atau keluarga merupakan sumber informasi yang paling bisa dipercaya oleh konsumen, karena mereka melihat sendiri sayuran hidroponik yang dikonsumsi.

Begitu pula pada konsumen sayuran non hidroponik. Sumber informasi yang paling berpengaruh bagi konsumen sayuran non hidroponik yaitu diri sendiri (40.48 persen), kemudian sumber informasi yang berasal dari pedagang sayuran sebanyak 23.81 persen, sumber informasi dari media cetak/elektronik sebanyak 19.05 persen, dan sumber informasi dari teman/keluarga sebanyak 16.67 persen. Teman atau keluarga merupakan sumber informasi yang paling bisa dipercaya oleh konsumen, karena mereka melihat sendiri sayuran yang dikonsumsi.

Tabel 2. Pengenalan kebutuhan konsumen dalam pembelian sayuran hidroponik dan non hidroponik

\begin{tabular}{|c|l|c|c|c|c|}
\hline \multirow{2}{*}{ No } & \multirow{2}{*}{ Uraian } & \multicolumn{2}{|c|}{ Konsumen Sayuran Hidroponik } & \multicolumn{2}{c|}{$\begin{array}{c}\text { Konsumen Sayuran Non } \\
\text { Hidroponik }\end{array}$} \\
\cline { 3 - 6 } & & $\begin{array}{c}\text { Jumlah } \\
\text { (orang) }\end{array}$ & $\begin{array}{c}\text { Persentase } \\
\text { (persen) }\end{array}$ & $\begin{array}{c}\text { Jumlah } \\
\text { (orang) }\end{array}$ & $\begin{array}{c}\text { Persentase } \\
\text { (persen) }\end{array}$ \\
\hline 1 & Diri Sendiri & 15 & 35.71 & 17 & 40.48 \\
\hline 2 & Media cetak/elektronik & 9 & 21.43 & 8 & 19.05 \\
\hline 3 & Pedagang Sayuran & 10 & 23.81 & 10 & 23.81 \\
\hline 4 & Teman/Keluarga & 8 & 19.05 & 7 & 16.67 \\
\hline
\end{tabular}

\section{Evaluasi Alternatif}

Pada tahap ini konsumen membuat pertimbangan terbaik yang harus diambil dalam memenuhi kebutuhannya dengan cara memilih kriteria-kriteria tertentu yang relevan dengan keinginan dan kebutuhan untuk membuat keputusan pembelian sayuran. Berdasarkan hasil penelitian, sayuran yang beredar di Kota Bandar Lampung cukup banyak jenisnya dan bisa dibedakan menjadi sayuran hidroponik dan non hidroponik.

Informasi penting yang dicari oleh konsumen dalam pembelian sayuran hidroponik dan non hidroponik sebagian besar karena kualitas (76.19), sedangkan untuk atribut harga masing masing 14.29 persen dan 23.81 persen. Akan tetapi tidak ada konsumen non hidroponik yan mementingkan informais kemasan, hanya pada 9.52 persen konsumen sayuran hidroponik yang menganggap kemasan merupakan informasi penting.

Tabel 3. Evaluasi alternatif konsumen dalam pembelian sayuran hidroponik dan non hidroponik

\begin{tabular}{|c|c|c|c|c|c|}
\hline \multirow{2}{*}{ No } & \multirow{2}{*}{ Uraian } & \multicolumn{2}{|c|}{ Konsumen Sayuran Hidroponik } & \multicolumn{2}{|c|}{$\begin{array}{c}\text { Konsumen Sayuran Non } \\
\text { Hidroponik }\end{array}$} \\
\hline & & $\begin{array}{l}\text { Jumlah } \\
\text { (orang) }\end{array}$ & $\begin{array}{c}\text { Persentase } \\
\text { (persen) }\end{array}$ & $\begin{array}{l}\text { Jumlah } \\
\text { (orang) }\end{array}$ & $\begin{array}{c}\text { Persentase } \\
\text { (persen) }\end{array}$ \\
\hline 1 & $\begin{array}{cl}\text { Informasi Penting } \\
\text { - } & \text { Harga } \\
\bullet & \text { Kemasan } \\
\bullet & \text { Kualitas } \\
\end{array}$ & $\begin{array}{c}6 \\
4 \\
32\end{array}$ & $\begin{array}{c}14.29 \\
9.52 \\
76.19\end{array}$ & $\begin{array}{c}10 \\
0 \\
32\end{array}$ & $\begin{array}{c}23.81 \\
0.00 \\
76.19\end{array}$ \\
\hline 2 & $\begin{array}{ll}\text { Pertimbangan Memilih } \\
\text { - } \quad \text { Kebiasaan yang telah dilakukan } \\
\text { - } \quad \text { Mengikuti Orang Lain } \\
\text { - } \quad \text { Laku di Pasaran }\end{array}$ & $\begin{array}{c}39 \\
2 \\
1\end{array}$ & $\begin{array}{c}92.86 \\
4.76 \\
2.38\end{array}$ & $\begin{array}{l}35 \\
4 \\
3\end{array}$ & $\begin{array}{l}83.33 \\
9.52 \\
7.14\end{array}$ \\
\hline
\end{tabular}

Sutarni dkk (Proses Pengambilan Keputusan Pembelian Sayuran Hidroponik Di Kota Bandar Lampung) 
Sementara itu, faktor yang menjadi pertimbangan bagi konsumen untuk memilih membeli sayuran hidroponik maupun non hiroponik, sebagian besar dikarenakan kebiasaan yang telah dilakukan. Kemudian sebagian yang lain karena mengikuti konsumen lain dan karena mengikuti orang lain. Pada konsumen sayuran hidroponik, 92.86 persen konsumen menyatakan bahwa mereka membeli sayuran hidroponik karena kebiasaan yang telah dilakukan, 2.38 persen karena laku dipasaran, dan 4.76 persen karena mengikuti konsumen lain. Sedangkan pada konsumen sayuran non hidroponik, 83.33 persen menyatakan bahwa mereka membeli sayuran non hidroponik karena kebiasaan yang telah dilakukan, serta masing-masing 7.14 persen dan 9.52 karena laku dipasaran dan mengikuti konsumen lain.

\section{Keputusan Pembelian}

Pada tahap ini, konsumen mengambil keputusan mengenai sayuran apa yang akan dibeli dan dikonsumsi dalam rumahtangganya. Menurut Engel et al. (1995), niat pembelian digolongkan menjadi dua kategori yaitu pembelian terencana dan pembelian tidak terencana. Berdasarkan hasil penelitian menunjukkan bahwa konsumen sayuran hidroponik dan non hidroponik sebagian besar melakukan pembelian sayuran secara terencana, yaitu sudah direncanakan terlebih dahulu. Cara pembelian sayuran hidroponik dan non hidroponik oleh konsumen dapat dilihat pada Tabel 14.

Tabel 14. Keputusan pembelian konsumen dalam pembelian sayuran hidroponik dan non hidroponik

\begin{tabular}{|c|c|c|c|c|c|}
\hline \multirow[t]{2}{*}{ No } & \multirow[t]{2}{*}{ Uraian } & \multicolumn{2}{|c|}{ Konsumen Sayuran Hidroponik } & \multicolumn{2}{|c|}{$\begin{array}{c}\text { Konsumen Sayuran Non } \\
\text { Hidroponik }\end{array}$} \\
\hline & & Jumlah & Persentase & Jumlah & Persentase \\
\hline 1 &  & $\begin{array}{c}33 \\
9\end{array}$ & $\begin{array}{l}78.57 \\
21.43\end{array}$ & $\begin{array}{l}22 \\
20\end{array}$ & $\begin{array}{l}57.38 \\
47.62\end{array}$ \\
\hline 2 & $\begin{array}{l}\text { Faktor yang mempengaruhi pembelian } \\
\text { - } \quad \text { Sedang ada diskon/ promosi } \\
\text { - } \quad \text { Produk terlihat segar/baru }\end{array}$ & $\begin{array}{c}39 \\
3\end{array}$ & $\begin{array}{c}92.86 \\
7.14\end{array}$ & $\begin{array}{c}41 \\
1\end{array}$ & $\begin{array}{c}97.62 \\
2.38\end{array}$ \\
\hline
\end{tabular}

Konsumen sayuran hidroponik yang melakukan pembelian sayuran secara terencana sebanyak 78.57 persen, dan sisanya sebanyak 21.43 persen konsumen secara tidak terencana. Konsumen melakukan pembelian sayuran secara terencana karena sudah mempunyai informasi mengenai harga dan kualitas sayuran yang diinginkan. Demikian pula dengan konsumen sayuran non hidroponik, yang melakukan pembelian sayuran secara terencana adalah sebanyak 57.38 persen, dan sisanya sebesar 47.62 persen dilakukan secara tidak terencana.

Selain itu, faktor yang mempengaruhi konsumen sayuran hidroponik maupun non hidroponik yang melakukan pembelian sayuran, sebagian besar karena sedang ada diskon atau promosi, masing-masing sebanyak 92.86 persen dan 97.62 persen. Sedangkan sisanya masing-masing sebanyak 7.14 persen dan 2.38 persen konsumen membeli sayuran karena produk terlihat segar/baru.

\section{Perilaku Pasca Pembelian}

Setelah konsumen membeli dan mengkonsumsi sayuran, timbul suatu perubahan dalam menilai sayuran yang dibelinya dengan berdasarkan pada kenyataan yang sesuai di lapangan. Seluruh konsumen responden yang membeli sayuran non hidroponik menyatakan puas dengan sayuran yang dibelinya. Sedangkan, terdapat 4.76 persen konsumen sayuran hidroponik yang tidak puas dengan sayuran yang dibelinya. Kepuasan pembelian sayuran hidroponik dan non hidroponik dapat dilihat pada Tabel 5. 
Tabel 5. Evaluasi pasca pembelian konsumen dalam pembelian sayuran hidroponik dan non hidroponik

\begin{tabular}{|c|c|c|c|c|c|}
\hline \multirow{2}{*}{ No } & \multirow{2}{*}{ Uraian } & \multicolumn{2}{|c|}{$\begin{array}{c}\text { Konsumen Sayuran } \\
\text { Hidroponik }\end{array}$} & \multicolumn{2}{|c|}{$\begin{array}{c}\text { Konsumen Sayuran Non } \\
\text { Hidroponik }\end{array}$} \\
\hline & & $\begin{array}{l}\text { Jumlah } \\
\text { (orang) }\end{array}$ & $\begin{array}{c}\text { Persentase } \\
\text { (persen) }\end{array}$ & $\begin{array}{l}\text { Jumlah } \\
\text { (orang) }\end{array}$ & $\begin{array}{c}\text { Persentase } \\
\text { (persen) }\end{array}$ \\
\hline 1 & $\begin{array}{l}\text { Kepuasan Pembelian Sayuran } \\
\text { - } \quad \text { Puas } \\
\text { - Tidak Puas }\end{array}$ & $\begin{array}{c}40 \\
2\end{array}$ & $\begin{array}{c}95.24 \\
4.76\end{array}$ & $\begin{array}{c}42 \\
0\end{array}$ & $\begin{array}{c}100.00 \\
0.00\end{array}$ \\
\hline 2 & $\begin{array}{cc}\text { Jika Harga Sayuran Naik } \\
\text { - } & \text { Tetap Membeli } \\
\text { - } & \text { Tidak Membeli } \\
\end{array}$ & $\begin{array}{c}41 \\
1 \\
\end{array}$ & $\begin{array}{c}97.62 \\
2.38\end{array}$ & $\begin{array}{c}42 \\
0\end{array}$ & $\begin{array}{c}100.00 \\
0.00\end{array}$ \\
\hline 3 & $\begin{array}{c}\text { Jika Sayuran tidak tersedia di pasaran } \\
\text { - } \quad \text { Mencari di tempat lain } \\
\text { - } \\
\text { Membeli sayuran lain }\end{array}$ & $\begin{array}{l}25 \\
17\end{array}$ & $\begin{array}{l}59.52 \\
40.48\end{array}$ & $\begin{array}{l}26 \\
16\end{array}$ & $\begin{array}{l}61.90 \\
38.10\end{array}$ \\
\hline
\end{tabular}

Tingkat kepuasan dapat menumbuhkan loyalitas konsumen terhadap suatu produk. Menurut Solomon (2006), kepuasan konsumen sangat dipengaruhi oleh harapan mereka atas kualitas produk yang digunakan. Jika produk dapat memenuhi harapan konsumen maka pengaruh positif akan diberikan konsumen terhadap produk tersebut, namun sebaliknya jika produk gagal memenuhi harapan konsumen maka pengaruh negatif akan diberikan konsumen terhadap produk.

Keadaan konsumen dalam membeli suatu produk sangat dipengaruhi oleh harga produk itu sendiri. Berdasarkan hasil penelitian menunjukkan bahwa apabila harga sayuran hidroponik maupun non hidroponik mengalami kenaikan, maka sebagian besar konsumen masih akan tetap membeli sayuran tersebut. Hal ini karena para konsumen tersebut sudah sangat yakin dengan kualitasnya yang terjamin. Pada konsumen sayuran hidroponik, sebanyak 97.62 persen konsumen akan tetap membe li sayuran hidroponik biarpun harganya mengalami kenaikan, dan sisanya sebanyak 2.38 persen konsumen menyatakan tidak akan membeli sayuran tersebut. Bahkan pada konsumen sayuran non hidroponik, sebanyak 100 persen konsumen menyatakan masih akan tetap membeli sayuran walaupun harga sayuran tersebut mengalami kenaikan. Loyalitas konsumen terhadap sayuran hidroponik dan non hidroponik dapat dilihat pada Tabel 5. Alasan konsumen untuk tetap membeli sayuran dimaksud karena mereka sudah merasa yakin bahwa sayuran tersebut memiliki kualitas yang bagus dan terjamin serta adanya alasan bahwa sayuran sudah menjadi kebutuhan mereka untuk dikonsumsi sehari-hari.

Keputusan pembelian suatu jenis sayuran juga sangat dipengaruhi oleh ketersediaan sayuran. Berdasarkan hasil penelitian menunjukkan bahwa apabila sayuran yang akan digunakan tidak tersedia di lapang, maka sebagian besar konsumen sayuran hidroponik (59.52 persen) akan mencari sayuran tersebut di tempat lain, sisanya sebanyak 40.48 persen akan membeli sayuran lain. Tidak berbeda jauh dengan konsumen pengguna sayuran non hidroponik, sebanyak 61.90 persen konsumen akan mencari di tempat lain, dan sisanya sebanyak 38.10 persen akan membeli sayuran lain. Hal ini menunjukkan konsumen memiliki tingkat loyalitas yang tinggi.

\section{SIMPULAN DAN SARAN}

\section{Simpulan}

Konsumen dalam pengambilan keputusan pembelian sayuran hidroponik dan non hidroponik melalui tahap pengenalan kebutuhan, pencarian informasi, evaluasi alternatif, keputusan pembelian, dan evaluasi pasca pembelian 
DOI: http://dx.doi.org/10.25181/jofsa.v2i1.1052

Journal of Food System and Agribusiness Vol. 2 (1): 17-24

\section{DAFTAR PUSTAKA}

Ancok, D. (1997). Teknik penyusunan skala pengukuran. Yogyakarta: Pusat Penelitian Kependudukan Universitas Gadjah Mada.

Andersen, K. E. (1972). Introduction to communication theory and practice. Cummings Pub. Co..

Assael H. (1992). Consumer Behavior and Marketing Action. Fourth Edition. New York (USA): Kent Publishing Company. Del Hawkins, Roger JB.

Badan Pusat Statistic Propinsi Lampung. (2015). Lampung dalam Angka. Bandar Lampung.

Bishop, C. E., \& Toussaint, W. D. (1979). Pengantar Analisa Ekonomi Pertanian. Penerbit Mutiara.

Emiria, F., \& Purwandari, H. (2015). Pengembangan Pertanian Organik di Kelompok Tani Madya, Desa Kebonagung, Kabupaten Bantul, Daerah Istimewa Yogyakarta. Jurnal Penyuluhan, 10(2).

Engel, J.F., R.D. Blackwell, dan P.W. Miniard. (1995). Perilaku Konsumen Jilid 1 (6th ed). Jakarta: Binarupa Aksara.

Gaspersz V. (2001). Ekonomi Manajerial, Pembuatan Keputusan Bisnis. Jakarta: PT. Gramedia Pustaka Uta

Hibon, A., \& Crissman, C. C. (1996). Establishing seed potato prices: Concepts, procedures, and implications for research and training (No. 1996). International Potato Center.

Tantri, F., \& Abdullah, T. (2012). Manajemen Pemasaran. Jakarta: PT. Raja Grafindo Persada.

Yolandika, C., \& Nurmalina, R. (2017). Analisis Nilai Tambah Brokoli Kemasan Cv . Yan' S Fruits And Vegetable Di Kecamatan Lembang Bandung Barat. Journal of Food System and Agribusiness (JoFSA), 1(1), 33-40. Retrieved from http://jurnal.polinela-srv.id/index.php/JOFSA/article/view/84

Sutarni dkk (Proses Pengambilan Keputusan Pembelian Sayuran Hidroponik Di Kota Bandar Lampung) 